\title{
EDITORIAL Spirometry in primary care
}

See linked article by Levy et al.,

September issue 2009,18(3):130-47

\section{*Martin R Miller}

${ }^{a}$ Consultant Respiratory Physician, Department of Medicine, University Hospital Birmingham NHS Trust, Birmingham, UK

*Correspondence:

Dr Martin Miller,

Department of Medicine, University Hospital Birmingham NHS Trust,

Selly Oak Hospital, Birmingham,

B29 6JD,

UK

Tel: $+44(0) 1216278479$

Fax: $+44(0) 1216278292$

E-mail: Martin.Miller@uhb.nhs.uk

6th November 2009
Chronic obstructive pulmonary disease (COPD) is the lung disease currently under scrutiny, and a National Strategy (formerly National Service Framework) for COPD is due to be published shortly. The criteria for diagnosing COPD have changed over the years, and the diagnostic criteria applied will affect the classification and observed prevalence of COPD. ${ }^{1,2}$ It is clear that central to the diagnosis of COPD is the need to identify poorly reversible airflow obstruction - and this requires accurate spirometry to be performed. Much of the perceived unmet need in COPD management will be based in primary care, and when the criteria for diagnosis have been finalised we will need to obtain acceptable spirometry data for large numbers of people in a primary care setting.

The spirometry Standards Document by Levy et al., published in the most recent September issue of this journal, ${ }^{3}$ has set out how best to perform spirometry in primary care. This is a timely and effective contribution to ensuring that we are best placed to meet the future needs of patients with COPD. The paper starts with a broad assessment of the main issues involved in the task of performing spirometry in primary care, and proceeds to advise on types of equipment, indications for undertaking spirometry, how to undertake the tests, how to interpret the results, and finally details on quality control and training. This is an ambitious paper that meets the needs of clinicians performing spirometry in primary care.

When advising about equipment the authors clearly cannot name preferred devices, but the emphasis is now towards flow measuring devices with a 'spirometry station' set-up. Transducer technology has improved considerably over recent years and the stability of flow transducers now makes them acceptable for our purpose. The move for a system that allows data accumulation is a sensible one, since a permanent record that can be easily referenced if the tests are repeated is important when documenting how this disease runs over time. A key aspect when using flow transducers is the need for some of these to be calibrated on a regular basis. Details of all these calibrations need to be documented and retained for future reference. Some flow heads state that they don't need calibration, but regular checks on their performance by performing calibration checks ${ }^{4}$ are essential to be certain the instruments do not vary in their response over time. In essence a calibration check is a recording with a 3 litre syringe delivering a profile with different flows and documenting the volume recorded to be sure it is within accepted limits ${ }^{4}$ irrespective of the flow profile.

The authors emphasise that symptoms are key in deciding whether or not spirometry is indicated. It is helpful to see in the Levy paper $^{3}$ a table of relative contraindications for spirometry, as this aspect is often forgotten in other spirometry standards publications. In the context of COPD, middle aged smokers are of interest and it is still not clear if it is sensible to be testing subjects without symptoms. Currently there is no indication to be screening asymptomatic subjects. However, if screening were undertaken using the conventional lower limit of normal - i.e. the lower $90 \%$ confidence limit - then $5 \%$ of a normal population would be detected as abnormal when in fact they were normal (false positives). Such a study might suggest that the prevalence of COPD was $5 \%$ in the normal population, and this false positive effect needs to be taken into account when interpreting studies quoting the prevalence of COPD in the general population. When testing asymptomatic subjects it would be better to use a lower $95 \%$ confidence limit to define abnormal results, thus reducing the false positive rate to $2.5 \%$.

The section in the paper ${ }^{3}$ on how to perform the spirometry test is brief and to the point 
and gives the essentials for delivering high quality results. Other papers discuss some of the issues in greater detail. ${ }^{4}$ It is essential that manufacturers understand our needs and then help us get the best from our equipment. Their software needs to deliver to the user the prompts and help that will ensure we get the best results. For example, just indicating if or when a subject meets repeatability criteria is not as helpful as the instrument showing with each successive blow how many blows so far have an $\mathrm{FEV}_{1}$ within $250 \mathrm{mls}, 200 \mathrm{mls}$ and $150 \mathrm{mls}$ of each other - and likewise for FVC. This allows the user to know how close a subject is to achieving the required repeatability, and if this is not forthcoming then exactly how close did the subject get.

It is ambitious to tackle the interpretation of spirometry results, and five pages of this Standards Document ${ }^{3}$ are appropriately set aside for this important aspect. The authors endorse the ATS and ERS view ${ }^{5}$ that using lower limits of normal (LLN) based on the results from relevant population data from normal subjects is the right way to proceed. Adopting LLN to determine if a subject has an abnormal result is extremely important when spirometry is being undertaken on subjects with a relatively low a priori probability of disease. The importance of this recommendation cannot be overemphasised. The GOLD criterion of using an $\mathrm{FEV}_{1} / \mathrm{FVC}$ ratio $<0.7$ as the cut-off for defining airflow obstruction ${ }^{6}$ has too many false positives in older subjects and some false negatives in younger subjects (where early identification of disease is most crucial) which means this criterion is not acceptable. Falsely attributing a disease such as COPD to an individual might have far reaching consequences for their employment and psychological well being.

How best to express the degree of lung function abnormality is still uncertain, and until alternative methods are properly validated ${ }^{7}$ the authors recommend sticking with percent of predicted. ${ }^{3}$ For reversibility testing the paper reiterates the best guidance of using two criteria as thresholds: first is that the change should be significantly different from zero or random change (i.e.>200ml); and second, a change greater than $12 \%$ of the subject's predicted value suggests asthma. The latter comparison takes into account lung size in determining if the change is likely to be clinically significant. It is still worth remembering that in the context of COPD a change of $4 \%$ of the predicted value has been found to be associated with a change in performance that subjects could distinguish as being improved against the performance of their peers. ${ }^{8}$

When contemplating increasing the availability of spirometry for primary care patients, the best result for the patient is for this to be delivered in a primary care setting. With regard to quality control and professional training, lung function laboratories based in secondary care have the rigours of quality control, staff training and validation of the results well embedded. The authors give advice on how to deliver this in primary care. ${ }^{3}$ This is potentially the weakest link in the delivery of quality spirometry, but the ERS has a Task Force addressing this issue. By the networking of lung function technicians with repeated feedback and training it must be possible to deliver the quality spirometry that is needed in primary care. However, there is more than one way to deliver a spirometry service, and some may choose to use the services of local secondary care services rather than set up a completely new service. ${ }^{9}$

In conclusion, the paper by Levy et al..$^{3}$ is a generous start and sets the way for spirometry in primary care to develop. Primary care clinicians will be well served by the breadth and scope of the authors' achievement. The difficult part of delivering quality spirometry in primary care now begins. Do we permanently equip primary care facilities to undertake spirometry, or arrange for visiting teams of trained staff with portable equipment to service the needs of practices on designated days? ${ }^{9}$ Various types of flow heads now just plug into the USB port of any computer, and so the latter approach is feasible and attractive.

\section{Conflict of interest declaration}

The author has no conflict of interest relating to this article.

\section{References}

1. Swanney MP, Ruppel G, Enright PL, et al. Using the lower limit of normal for the $\mathrm{FEV}_{1} / \mathrm{FVC}$ ratio reduces the misclassification of airway obstruction. Thorax 2008;63:1046-51. http://dx.doi.org/10.1136/thx.2008.098483

2. Shirtcliffe $P$, Weatherall M, Marsh $S$, et al. COPD prevalence in a random population survey: a matter of definition. Eur Respir J 2007;30:232-9. http://dx.doi.org/10.1183/09031936.00157906

3. Levy ML, Quanjer PH, Booker R, Cooper BG, Holmes S, Small I. Diagnostic spirometry in primary care: Proposed standards for general practice compliant with American Thoracic Society and European Respiratory Society recommendations: a General Practice Airways Group (GPIAG) document, in association with the Association for Respiratory Technology \& Physiology (ARTP) and Education for Health. Prim Care Resp J 2009;18:130-47. http://dx.doi.org/10.4104/pcrj.2009.00054

4. Miller MR, Hankinson J, Brusasco V, et al. Standardisation of spirometry. Eur Respir J 2005;26:319-38.

5. Pellegrino R, Viegi G, Brusasco $V$, et al. Interpretative strategies for lung function tests. Eur Respir J 2005;26:948-68. http://dx.doi.org/ 10.1183/09031936.05.00035205

6. Miller MR, Pedersen OF, Pellegrino R, Brusasco V. Debating the definition of airflow obstruction: time to move on? Eur Respir J 2009;34:527-8. http://dx.doi.org/10.1183/09031936.00103309

7. Miller MR, Pedersen OF. New concepts for expressing FEV 1 arising from survival analysis. Eur Respir J 2009; Epub 11/9/2009.

8. Redelmeier DA, Goldstein RS, Min ST, Hyland RH. Spirometry and dyspnea in patients with COPD. When small differences mean little. Chest 1996;109: 1163-8. http://dx.doi.org/10.1378/chest.109.5.1163

9. Enright P. Provide GPs with spirometry, not spirometers. Thorax 2008;63: 387-8. http://dx.doi.org/10.1136/thx.2007.092916

Available online at http://www.thepcrj.org 